\title{
Characteristics of Dental Treatment in two months' Quarantine due to Coronavirus Disease (COVID-19)
}

\author{
Elka Nikolaeva Radeva
}

\author{
Associate Professor, Department of Conservative Dentistry, Faculty of Dental Medicine, Medical University, Sofia, Bulgaria \\ DOI: 10.29322/IJSRP.10.08.2020.p10470 \\ http://dx.doi.org/10.29322/IJSRP.10.08.2020.p10470
}

\begin{abstract}
Introduction: Novel coronavirus disease was announced on January 30, 2020, by the World Health Organization (WHO). On March 13, 2020 many dental offices closed due to the impending danger. Patients were discharged from the schedules without a clear idea of when normal dental activity would resume. Under such circumstances, a lot of patients with pain, caries or fracture restoration had to wait for dental care during these two months. The aim of the current study is to analyze the character of the dental complains and treatment immediately after 2 months of quarantine due to COVID-19; and to consider proposals and strategies for infection control in the new situation. Materials and methods: The study included patients who visited general dental practice in the period of May 14 - June 14, 2020. Patient information about gender, age and diagnosis were analyzed. The obtained body temperatures and the questionnaires for the epidemiological study of COVID-19 were reviewed. The data are compared with those for the same period May 14 - June 14, 2019. The results of the conducted study are presented graphically and represent the percentage distribution of gender, age and diagnosis. Results: For both periods of time the percentage of female who visited dental practice is higher - 53\% for 2020 and $57 \%$ for 2019 , than male percentage $-47 \%$ for 2020 and $43 \%$ for 2019 , respectively. The highest percentage (47\%) of patients who visited the dental practice in two months' quarantine were aged 41-50, compared to the year of 2019 when the highest percentage (31\%) of patients were aged 61-70 and 24\% - 51-60. The highest percentage $(41 \%)$ of patients in two months' quarantine in the year of 2020 were with fracture of restoration or tooth fracture and $20 \%$ turned out to be with irreversible pulpitis. Within the same period of time in 2019, treatment of apical periodontitis $-39 \%$ and restorations/caries treatment - $33 \%$ were most prevalent.

Prosthetic reasons for the study period of one month in 2020 were $15 \%$, while for $2019-6 \%$. Periodontal reasons $-18 \%$ cases were registered for 2020, and 9\% - for 2019. Conclusions: In two months' quarantine the patients look for dental care only in case of pain (irreversible pulpitis, symptomatic periodontitis) or tooth/restoration/crown fracture. In pandemic situation during COVID-19 outbreak, personal protective equipment and patient screening are considered to be of great importance in protecting dental staff and patients.
\end{abstract}

Index Terms- coronavirus disease, dental treatment, protective equipment

This publication is licensed under Creative Commons Attribution CC BY.

http://dx.doi.org/10.29322/IJSRP.10.08.2020.p10470

\section{INTRODUCTION}

$\mathrm{N}$ ovel coronavirus disease was announced on January 30, 2020, by the World Health Organization (WHO). WHO declares danger to public health of international importance following global spread of infection complicated by (Corona Virus Disease, COVID-19) [1, 2].

The new 2019-nCoV, which started in Wuhan, Hubei Province in China, belongs to the $\beta$ - coronaviruses. This virus mainly affects the respiratory, digestive and central nervous systems of humans [3].

The main routes of transmission include via respiratory droplets (sneezing, coughing, talking and aerosols) and contact transmission (contact with the oral, nasal and ocular mucosa) [4, 5]. Transmission of the virus can also occur through direct contact with asymptomatic patients. The asymptomatic incubation period for SARS-CoV-2 infected patients is within 2 - 14 days.

The clinical symptoms of patients are as follows: fever, dry cough, sore throat, fatigue, muscle pain, severe exhaustion. Less typical symptoms involve headache, sputum, diarrhea and vomiting $[3,6]$.

In dental practices, staff is at extremely high risk of SARSCoV-2 infection due to direct contact with saliva, blood, aerosols when working with high-speed handpieces and ultrasound devices $[1,3,4,7]$. Pathogenic microorganisms can be transmitted in the dental office by inhaling airborne microorganisms and viral particles that can remain dispersed for a long period of time. These drops fall quickly on the floor, surrounding work surfaces, medical staff or patient. SARS-CoV-2 can persist over the surfaces for a few hours up to several days depending on temperature and humidity $[1,8]$. The transmission path is also the indirect contact with contaminated instruments or surfaces from the environment. Effective infection control strategies are needed to prevent the spread of COVID-19 by contact.

On March 13, 2020 many dental offices closed due to the impending danger. Patients were discharged from the schedules without a clear idea of when normal dental activity would resume. There was neither enough personal protective equipment nor disinfectants. A lot of patients with pain, caries or fracture restoration had to wait for dental care over this two months' period.

After two months (from 13 March to 14 May) emergency epidemiological situation was introduced - from 14 May, 2020 until June 14, 2020 - during which the measures were gradually relaxed and society moved to a more normal life [9]. Throughout 
this period, the admission of patients with strict selection and observance of strict anti-epidemic measures began slowly.

The aim of the current study is to analyze the character of the dental complains and treatment immediately after 2 months of quarantine due to COVID-19 and to consider proposals and strategies for infection control in the new situation.

\section{MATERIALS AND METHODS}

The study included patients who visited general dental practice in the period of May 14 - June 14, 2020. Patients admitted to the waiting room wear a surgical mask. The schedule is designed so that there is only one patient in the waiting room. When entering the office, patients disinfect their hands. The body temperature of each patient is taken with a DT8018 non-contact thermometer. Patients who have shown normal body temperature complete a screening questionnaire for potential patients with SARS-CoV-2. The following four questions are included:

- Have you had a fever for the last 14 days? Have you had eye inflammation, dry cough, difficulty breathing or other flu-like complaints?

- Have you travelled outside the borders of the Republic of Bulgaria for the last 14 days?

- Have you been in contact with people coming from risk areas for the last 14 days?

- Have you been in contact with people with confirmed SARS-CoV-2 infection for the last 14 days?

Diagnoses were based on patient complains and clinical investigations. The main diagnoses were - Irreversible pulpitis,
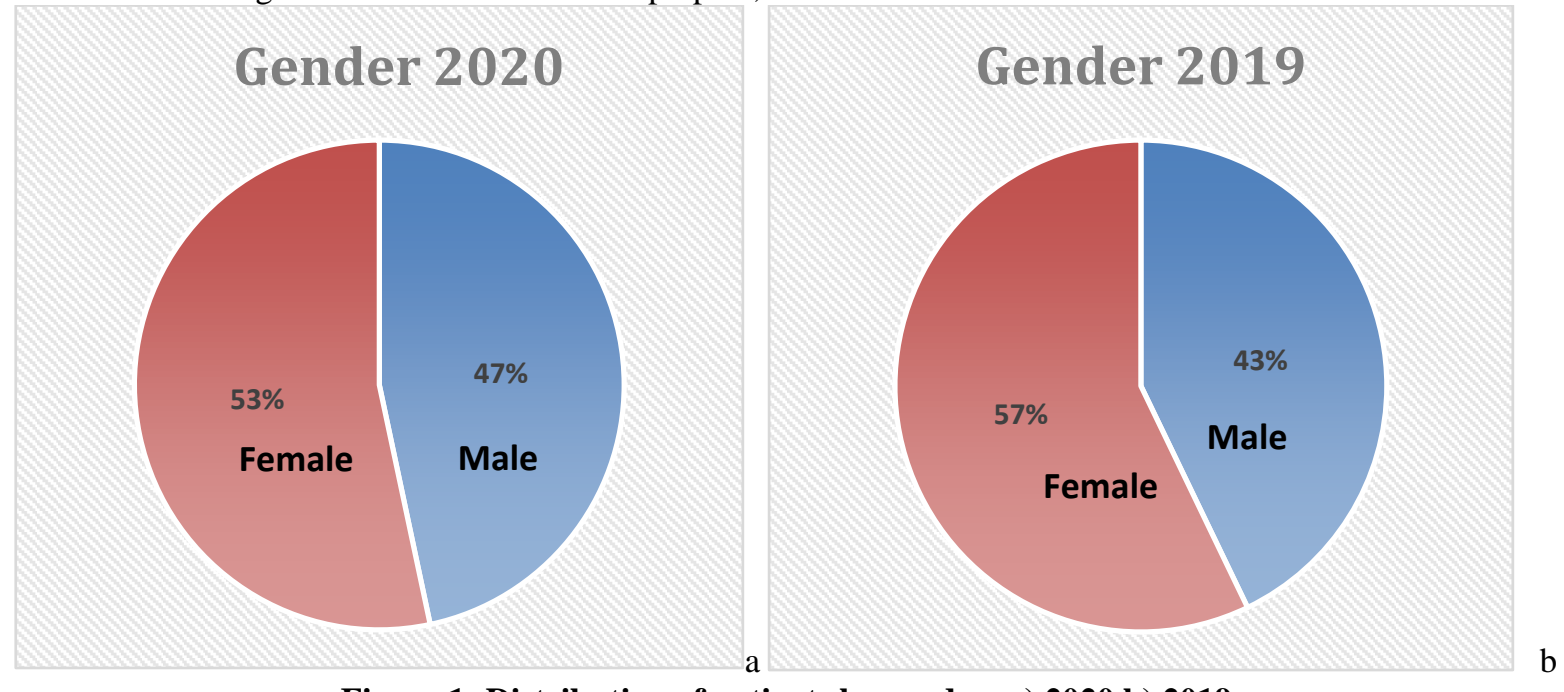

Figure 1: Distribution of patients by gender: a) 2020 b) 2019

The highest percentage (47\%) of patients who visited the dental practice in two months' quarantine were aged 41-50, compared to the year of 2019 when the highest percentage (31\%) of patients were aged 61-70 and 24\% - 51-60 (Fig.2). 

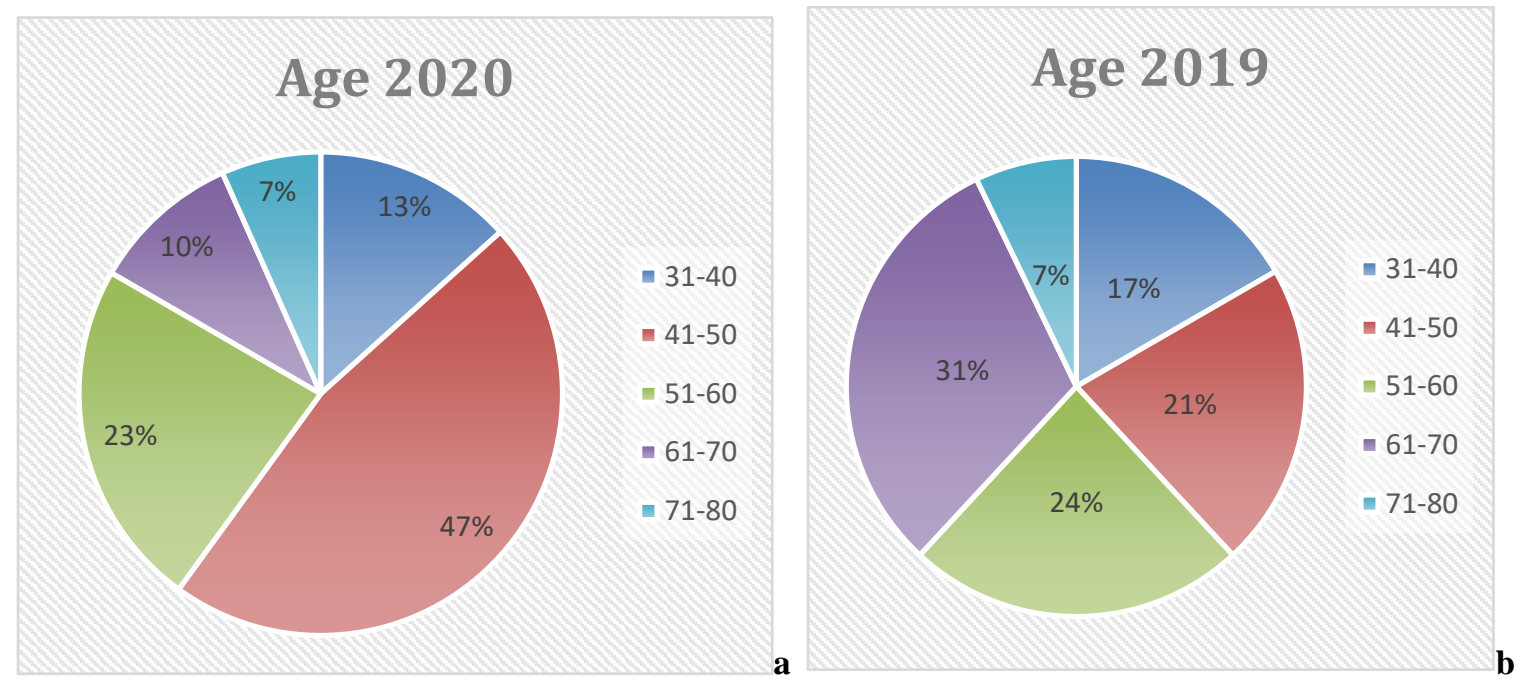

Figure 2: Distribution of patients by age a) 2020 b) 2019

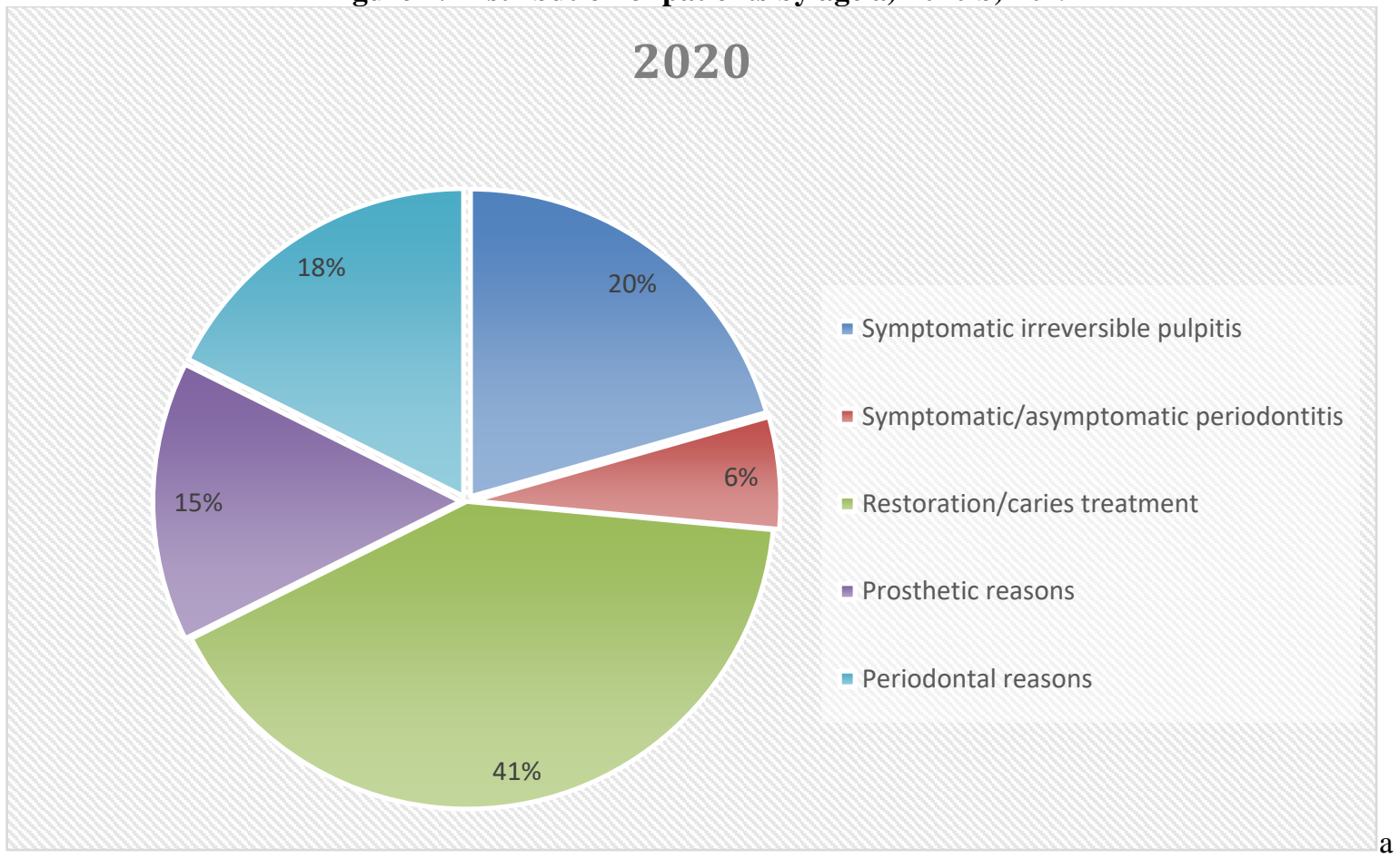




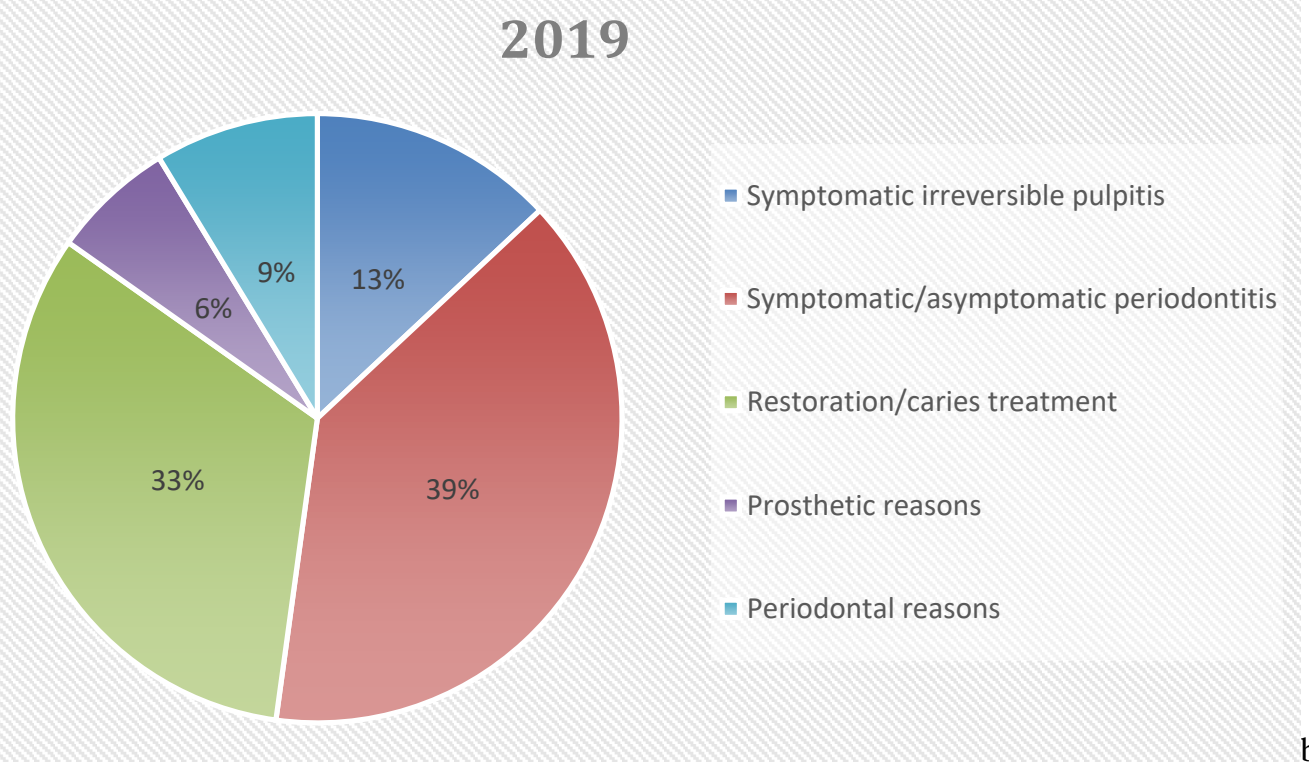

Figure 3: Percentage distribution of diagnosis for period a) 14 May to 14 June 2020; b) 14 May to 14 June 2019

The highest percentage $(41 \%)$ of patients in two months' quarantine in the year of 2020 were with fracture of restoration or tooth fracture and $20 \%$ turned out to be with irreversible pulpitis. Within the same period of time in 2019, treatment of apical periodontitis - 39\% and restorations/caries treatment - 33\% were most prevalent.

Prosthetic reasons for the study period of one month in 2020 were $15 \%$, while for $2019-6 \%$. Periodontal reasons $-18 \%$ cases were registered for 2020 and 9\% - for 2019 (Fig.3).

\section{DISCUSSION}

The diagnosis of COVID-19 is a combination of epidemiological information, clinical symptoms and laboratory tests (PCR). The incubation period is between 2 and 14 days and during this period patients can infect other people.

Fever is one of the leading symptoms of coronavirus infection $(98 \%)[10,11]$. No patients with fever were identified in the present study. No patients were found to have answered "yes" to any of the questions. Of all the patients, examined and undergone treatment within the period of 14 May - 14 June, no case of SARS - CoV -2 infection was identified. At the end of dental treatment for that period 12 patients have made a PCR test voluntarily and all of them were negative.

Hand hygiene is another important factor for reducing the risk of transmission of SARS-CoV-2. All patients disinfect their hands using an alcohol based sanitizer when entering the office. Dentists should wash their hands before examining a patient, before handling and after touching surrounding surfaces that have not been disinfected. Besides, dentists ought to be careful and avoid touching their own eyes, nose and mouth [1].

Rinsing with antibacterial mouthwash at the beginning of dental procedures reduces significantly microbial load. A study used meta-analysis of 12 studies showed that pre-procedural mouth rinses with chlorhexidine, cetylpyridinum chloride and essential oils (eucalyptol, menthol, thymol, lemon oil, tea tree oil) reduced considerably the number of microorganisms in the dental aerosol $[12,13]$. Dental aerosols may contain particles from saliva, blood, tooth debris, dental plaque or dental filling materials, and generated from the high-speed hand piece, ultrasonic devices or water/air spray. Such particles have a diameter of $50 \mu \mathrm{m}$ or less [8].

In two months' quarantine and prolong waiting for dental treatment to initiate, fracture of restoration or tooth fracture $(41 \%)$ and irreversible pulpitis - 20\% turned out to be most frequent patient complaints. In three of cases with fixed appointment for caries treatment before March 13, the patient diagnosis was complicated into pulpitis due to delayed untimely visit. Over that period patients reported of higher level of anxiety concerning their teeth and impossibility to do anything for them. Yu J. et al. observed emergency treatment from 22 February to 2 March, 2020 in emergency department of the School and Hospital of Stomatology at Wuhan University. They found out that the most common emergency cases $(50.26 \%)$ were with symptomatic irreversible pulpitis compared to the year of 2019, when emergency cases were $13.47 \%$ [10]. Guo et al. reported for less dental trauma during period of isolation [14].

Coronavirus disease has a high spreading potential. People of all ages are susceptible to this coronavirus infection [1]. Elderly patients with chronic diseases have a higher risk of infection than young patients with strong immune system [13]. The highest percentage $(47 \%)$ of patients who visited dental practice in a twomonth quarantine are aged 41-50, compared to the year of 2019 when the highest percentage (31\%) of patients having used dental service were aged 61-70 and 24\% - 51-60. Elderly patients (over aged 60) are afraid to visit a dental parctitioner for longer procedures especially in case of delay.

During COVID-19 pandemic, dentists are at high risk of infection. Reducing treatment time and exposure control are two ways to diminish the risk of infection [10]. Routine dental procedures have been delayed, completely depending on epidemic situation. For 2019, 39\% of clinical cases were with asymptomatic apical periodontitis compared to 2020 when predominant cases were with fracture of restoration or tooth fracture (41\%). In pandemic situation patients look for dental care only in case of 
pain. They tend to wait for treatment which can be delayed. Regarding periodontal cases $(18 \%)$ in our study for the year of 2020 - hand scalers were used, while in 2019 (9\%) -ultrasonic scalers were applied.

In an emergency epidemiological situation, a number of precautions should be taken by dentists. Being equipped with disposable N95 masks, gloves, eyeglasses, face shields, caps and gowns is a must. In dental office - UV lamps for disinfection and air purifier need to be available [10].

At the end of dental treatment for the period of our study (14 May - 14 June 2020), 12 patients have made a PCR test voluntarily and all of them were negative. This outcome undoubtedly suggests that the protective measures were effective in protecting patients during COVID-19 infection. None of the other patients had complaints of health deterioration.

\section{CONCLUSIONS}

In two months' quarantine the patients look for dental care only in case of pain (irreversible pulpitis, symptomatic periodontitis) or tooth/restoration/crown fracture. In pandemic situation during COVID-19 outbreak, personal protective equipment and patient screening are determined to be of great importance in protecting both patients and dental staff.

\section{REFERENCES}

[1] Meng L., F. Hua, Z. Bian. Coronavirus Disease 2019 (COVID-19):Emerging and Future Challenges for Dental and Oral Medicine. Journal of Dental Research 2020, Vol. 99(5) 481-487

[2] Chen, J. Pathogenicity and transmissibility of 2019-nCoV-A quick overview and comparison with other emerging viruses. Microbes Infect. 2020, 22, 69-71.

[3] Giudice R. The Severe Acute Respiratory Syndrome Coronavirus-2 (SARS CoV-2) in Dentistry. Management of Biological Risk in Dental Practice. Int. J. Environ. Res. Public Health 2020, 17, 3067; doi:10.3390/ijerph17093067

[4] Peng, X.; Xu, X.; Li, Y.; Cheng, L.; Zhou, X.; Ren, B. Transmission routes of 2019-nCoV and controls in dental practice. Int. J. Oral Sci. 2020, 12, 1-6.
[5] Ge, Z.; Yang, L.; Xia, J.; Fu, X.; Zhang, Y. Possible aerosol transmission of COVID-19 and special precautions in dentistry. J. Zhejiang Univ. B 2020, 1-

[6] Guan, W.; Ni, Z.; Hu, Y.; Liang, W.; Ou, C.; He, J.; Liu, L.; Shan, H.; Lei, C.; Hui, D.S.C.; et al. Clinical Characteristics of Coronavirus Disease 2019 in China. N. Engl. J. Med. 2020.

[7] Sabino-Silva R, Jardim A, Siqueira W. Coronavirus COVID-19 impacts to dentistry and potential salivary diagnosis. Clinical Oral investigations, 2020, 24:1619-1621

[8] Jain M, A. Mathur, A. Mathur, P. Mukhi, M, Ahire, C. Pingal. Qualitative and quantitative analysis of bacterial aerosols in dental clinical settings: Risk exposure towards dentist, auxiliary staff, and patients. J Family Med Prim Care. 2020 Feb; 9(2): 1003-1008

[9] Танева С. Й. Поведенческая модель во время пандемии (Covid-19) на основе анкетного опроса студентов из Медицинского университета Болгарии // Здоровье человека, теория и методика физической культуры и спорта, 2020. Т. 19. № 3. С. 4-16. URL: http://journal.asu.ru/zosh/article/view/8126.

[10] Yu J, T. Zhang, D. Zhao, M. Haapasalo, Y. Shen. Characteristics of Endodontic Emergencies during Coronavirus Disease 2019 Outbreak in Wuhan. JOE Volume 46, Number 6, June 2020, 730-735

[11] Huang C., Wang Y., Li X, , Ren L, Zhao J, Hu Y, Zhang L, et al., Clinical features of patients infected with 2019 novel coronavirus in Wuhan, China. Lancet 2020; 395:497-506

[12] Marui, V.C.; Souto, M.L.S.; Rovai, E.S.; Romito, G.A.; Chambrone, L.; Pannuti, C.M. E_cacy of preprocedural mouthrinses in the reduction of microorganisms in aerosol: A systematic review. J. Am. Dent. Assoc. 2019, 150, 1015-1026.e1.

[13] Ahmed M, R. Jouhar, N. Ahmed, S. Adnan, M. Aftab, M. Zafar, Z. Khurshid Fear and Practice Modifications among Dentists to Combat Novel Coronavirus Disease (COVID-19) Outbreak. Int J of Environ. Research and Public Health, 2020, 17:2821

[14] Guo, H.; Zhou, Y.; Liu, X.; Tan, J. The impact of the COVID-19 epidemic on the utilization of emergency dental services. J. Dent. Sci. 2020.

\section{AUTHORS}

First Author - Elka Nikolaeva Radeva, Associate Professor, Department of Conservative Dentistry, Faculty of Dental Medicine, Medical University, Sofia, Bulgaria

e-mail: eliradeva@abv.bg 